\title{
PENERAPAN MODEL COOPERATIVE LEARNING TIPE JIGSAW TERHADAP HASIL BELAJAR KETERAMPILAN POOMSAE I MATA KULIAH TAEKWONDO
}

\author{
Cucu Hidayat ${ }^{1 *}$, Dicky Tri Juniar ${ }^{2}$, Melya Nur Herliana ${ }^{3}$ \\ ${ }^{1}$ Jurusan Pendidikan Jasmani, Fakultas Keguruan dan Ilmu Pendidikan Universitas Siliwangi \\ Jl. Siliwangi No. 24 Tasikmalaya 46115 Telp. (0265) 323537 \\ email : teje1986@gmail.com
}

\begin{abstract}
Abstrak
Tujuan penelitian ini secara umum tujuan penelitian ini adalah untuk mengetahui penerapan model cooperative learning terhadap peningkatan hasil belajar keterampilan poomsae I mata kuliah Taekwondo. Secara khusus penelitian ini bertujuan untuk mengetahui penerapan model cooperative learning terhadap peningkatan hasil belajar keterampilan poomsae I pada mahasiswa PJKR yang mengontrak mata kuliah taekwondo tahun ajaran 2016-2017. Pada penelitian yang penyusun lakukan ini, peneliti menggunakan metode penelitian yang penulis lakukan yaitu dengan menggunakan metode penelitian tindakan (action research). Sampel yang diambil dengan cara purposive sampling karena ditentukannya kelas yang paling rendah kualitas keterampilannya dibandingkan kelas yang lain. Hasil penelitiannya menunjukkan pada siklus I ketuntasan belajar mahasiswa masih berada pada 70,5\% yaitu terdapat 28 orang yang sudah menunjukkan ketuntasan belajarnya. Siklus II sudah menunjukkan peningkatan yang signifikan yaitu sudah sampai $87,5 \%$ (35 orang) yang sudah tuntas belajar atau dikatakan lulus. Bagi para pelaksana olahraga terutama guru penjaskes perlu kiranya menerapkan model pembelajaran kooperatif tipe jigsaw pada mata pelajaran beladiri terutama taekwondo.
\end{abstract}

Kata kunci: Penerapan, Jigsaw \& Poomsae

\begin{abstract}
The purpose of this study in general the purpose of this study is to determine the implementation of cooperative learning model to improve learning outcomes skills poomsae I Taekwondo courses. Specifically this research aims to find out the implementation of cooperative learning model to improve the learning outcomes of poomsae I skills in PJKR students contracting taekwondo courses for the academic year 2016-2017. In the study that the authors do this, the researcher uses research methods that the authors do is by using the method of action research (action research). The sample is taken by purposive sampling because it determines the lowest grade of skill quality compared to the other class. The results showed that in the cycle I mastery of student learning is still at $70.5 \%$ ie there are 28 people who have shown mastery learning. Cycle II has shown a significant increase that is up to $87.5 \%$ (35 people) who have completed study or graduation. For sports practitioners, especially teachers of pemaskes need to apply cooperative learning model type jigsaw on martial arts especially taekwondo.
\end{abstract}

Keywords: Application, Jigsaw \& Poomsae. 


\section{PENDAHULUAN}

Pendidikan merupakan kegiatan yang harus dilaksanakan oleh setiap orang. Pendidikan sifatnya wajib dalam rangka untuk mewujudkan cita-cita bangsa dan negara agar menjadi manusia yang cerdas baik akal, pikiran dan hati. Menurut wikipedia (2016), pendidikan adalah pembelajaran pengetahuan, keterampilan, dan kebiasaan sekelompok orang yang diturunkan dari satu generasi ke generasi berikutnya melalui pengajaran, pelatihan, atau penelitian. Dalam hal ini pendidikan yang biasa dilakukan secara formal baik di sekolah maupun di perguruan tinggi, yang menekankan peningkatan kemampuan baik kognitif, afektif dan bahkan psikomotornya.

Dalam UU No. 20 tahun 2003 bahwa pendidikan adalah usaha sadar dan terencana untuk mewujudkan suasana belajar dan proses pembelajaran agar proses peserta didik secara aktif mengembangkan potensi dirinya untuk memiliki kekuatan spiritual keagamaan, pengendalian diri, kepribadian, kecerdasan akhlak mulia, serta keterampilan yang diperlukan dirinya, masyarakat, bangsa dan negara. Sehingga diharapkan dalam proses pembelajaran peserta didik mampu mengembangkan segala kemampuan dirinya untuk menggali potensi lebih dalam lagi agar tercapai tujuan pendidikan yang diharapkan dan bisa bermanfaat bagi msyarakat.

Tujuan pendidikan pada hakekatnya untuk mengembangkan potensi peserta didik agar menjadi manusia yang beriman dan bertakwa kepada Tuhan Yang Maha Esa, berakhlak mulia, sehat, berilmu, cakap, kreatif mandiri, dan menjadi warga negara yang yang demokratis serta bertanggung jawab. Dalam membentuk manusia yang berkualitas maka harus menyelenggarakan pendidikan yang berkualitas juga dengan didukung dari berbagai lini kehidupan mulai dari sekolah, masyarakat, dan sampai pada keluarga. Namun pada kenyataanya orang tua berfikir hanya sekolah yang mampu memberikan pendidikan dan perubahan menyeluruh kepada anak-anaknya tanpa melihat segala keterbatasan yang diperoleh. Tapi sebagai wadah pendidikan yang formal, sekolah harus memberikan seluruh pelayanannya dengan baik dalam penyelenggaraan pendidikan agar mampu menghasilkan peserta didik yang berkualitas dan bermanfaat.

Pembelajaran yang dilaksanakan pada pendidikan tinggi lebih mengutamakan aktualisasi diri dari peserta didik atau mahasiswa itu sendiri. Sehingga kesempatan yang diberikan oleh pendidik harus lebih terbuka lebar dalam mengembangkan potensi yang dimiliki mahasiswa. Terutama di jurusan Pendidikan, Jasmani, Kesehatan dan Rekreasi yang secara substansinya perbandingan mata kuliah teori dan prakteknya hampir sama, sehingga selain teori harus dipahami mahasiswa juga harus menguasai secara praktik dengan baik. Salah satu mata kuliah yang memberikan pendidikan bagi mahasiswa di Jurusan Pendidikan, Jasmani, Kesehatan dan Rekreasi adalah Teori dan Praktek Taekwondo. Mata kuliah ini adalah salah satu mata kuliah pilihan yang diberikan kepada mahasiswa dengan tujuan untuk memberikan pengetahuan dan pengalaman dalam mengenal olahraga beladiri taekwondo.

Hasil belajar dari mata kuliah taekwondo adalah mahasiswa mampu memahami dan mempraktikkan seluruh teknik-teknik taekwondo dan peraturan pertandingan yang biasa dilaksanakan dalam suatu kejuaraan. Sehingga implikasinya pada mahasiswa mampu membimbing atau melatih peserta didik pada saat melakukan Program Latihan Profesi (PLP) di sekolah-sekolah. Bahkan bisa menjadi bekal setelah lulus nanti apabila mengabdi menjadi seorang guru mampu membimbing atau mengajar materi taekwondo kepada siswa-siswanya. Paradigma masyarakat sekarang ini nilai yang layak harus dimiliki mahasiswa dalam ketuntasan belajarnya adalah nilai A dan B. Walaupun secara akademik dan aturan yang berlaku bahwa nilai yang dianggap sudah layak atau tuntas belajar adalah minimal nilai C. Tetapi 
sesuai dengan visi dan misi Fakultas Keguruan dan Ilmu Pendidikan yang mentargetkan nilai IPK harus mencapai minimal 3,00 maka setiap mahasiswa harus mendapat nilai minimal rata-rata B.

Pada kenyataanya yang terjadi setiap tahun nilai rata-rata yang didapat mahasiswa yang mengontrak mata kuliah praktek taekwondo terutama pada kajian materi poomsae adalah nilai $\mathrm{C}$, sehingga masih belum dikatakan tuntas belajar. Sebab tersebut adalah jumlah mahasiswa yang relatif banyak sehingga proses pembelajaran yang semakin sulit terkendali dan tidak kondusif. Apalagi dengan metode yang digunakan masih klasikal yaitu metode yang berpusat pada dosen, yang memungkinkan mahasiswa merasa cepat bosan dan jenuh sehingga materi yang disampaikan tidak dipahami dan tidak dikuasai.

Formula baru perlu dikembangkan dan ditingkatkan untuk perubahan proses pembelajaran yang lebih kondusif, kreatif dan menyenangkan. Model pembelajaran kooperatif tipe jigsaw adalah salah satu metode pembelajaran yang bisa memberikan warna baru dalam proses pembelajaran praket taekwondo. Pembelajaran kooperatif tipe jigsaw merupakan gabungan model interaksional dan filsafat mengajar yang mengembangkan kerjasama antar peserta didik sendiri dan belajar dari teman (Munasih;2016). Pada prosesnya peserta didik dibagi menjadi beberapa kelompok belajar yang heterogen, didalamnya diberikan materi yang berbeda-beda setiap orangnya. Dimungkinkan mahasiswa akan saling memberikan motivasi dan berbagi pengetahuan sehingga materi yang terpisah tersebut menjadi satu kesatuan materi yang utuh. Maka akan berkembangnya peran mahasiswa yang berawal dari pembelajar pasif menjadi pembelajar aktif.

Bukan hanya dari segi keaktifannya saja melainkan keterampilannya pun jelas akan meningkat dengan signifikan, karena dengan proses pembelajaran yang kondusif dan interaktif serta menarik akan memeberikan pengaruh motivasi besar bagi peserta didik khususnya mahasiswa yang mempunyai karakteristik kritis, aktif, komunikatif dan interaktif. Dalam hal ini karena mata kuliah taekkwondo lebih kepada penerapan aktifitas praktik sehingga lebih mengutamakan keterampilan dan keatifannya saja dibandingkan menanamkan pengetahuannya. Sehingga penulis pada kesempatan ini mengutamakan peningkatan keterampilan gerak dan komunikasi sosial dengan temannya.

Belajar dibutuhkan sepanjang hidup, karena dengan belajar segala hal yang diharapkan kemungkinan besar akan bisa tercapai. Apalagi dengan adanya UU No. 20 tahun 2003 tentang sistem pendidikan nasional yang didalamnya menjelaskan mengenai kewajiban belajar hingga usia 15 tahun. Dalam mewadahi proses belajar yang baik dan bermutu maka pemerintah memfasilitasi suatu pendidikan mulai dari TK sampai Perguruan Tinggi, baik pendidikan bersifat formal, nonformal bahkan informal.

Dalam suatu proses pendidikan terdapat beberapa hal yang menjadi komponen penting dalam melihat perkembangan belajar seseorang atau peserta didik, diantaranya adalah hasil belajar. Hasil belajar merupakan komponen yang terintegrasi dalam suatu kegiatan pendidikan karena untuk melihat seberapa jauh perkembangan seseorang selama melaksanakan proses belajar.

Hasil belajar adalah sebagian kemampuan yang dimiliki siswa setelah ia menerima pengalaman belajar, yang berupa penampilan yang dapat diamati sebagai hasil belajar yang disebut kemampuan (Sudjana, 2013). Hasil belajar tidak akan muncul apabila pengalaman belajar yang diberikan tidak bermakna. Sehingga dibutuhkan suatu pengalaman yang bermakna dan mempunyai arti untuk memberikan perubahan terhadap seluruh komponen kompetensi baik itu pengetahuan, sikap atau keterampilan.Penilaian hasil belajar pada hakikatnya adalah suatu kegiatan untuk mengukur perubahan perilaku yang telah terjadi pada diri peseta didik (Mulyasa, 2009:208). Mulyasa mengatakan (2009:209) bahwa penilaian hasil belajar dapat dilakukan terhadap program, proses dan hasil belajar. Berkaitan dengan hal tersebut maka penilaian hasil bertujuan untuk mengetahui hasil belajar atau pembentukan kompetensi peserta didik. 
Standar penilaian pembelajaran merupakan kriteria minimal tentang penilaian proses dan hasil belajar mahasiswa dalam rangka pemenuhan capaian pembelajaran lulusan. Penilaian proses dan hasil belajar harus sesuai dengan prinsip-prinsip penilaian yaitu: edukatif, otentik, ebjektif, akuntabel dan transparan yang dilakukan secara terintegrasi (Permenristekdikti No. 44 tahun 2015). Pada praktiknya dalam mata kuliah taekwondo sudah melakukan penilaian sesuai dengan prinsip-prinsip penilaian yang sudah dijelaskan diatas, sehingga mahasiswa dari tahun ke tahun selalu merasa puas dengan hasil yang didapatnya, walaupun masih banyak yang belum dikatakan tuntas belajar. Aktivitas pembelajaran yang memberikan pengalaman yang baik dan berkualitas tentunya membutuhkan perencanaan yang matang. Pembelajaran yang kreatif adalah pembelajaran yang mampu untuk menciptakan, mengimajinasikan, melakukan inovasi dan melakukan hal-hal yang artistik lainnya (Ahmadi \& Sofan Amri, 2011:3).

Sebagaimana dalam Permenristekdikti No. 44 tahun 2015 bahwa lulusan yang diharapkan adalah mahasiswa yang mempunyai sikap dan perilaku yang benar serta berbudaya sebagai hasil dari internalisasi dan aktualisasi nilai dan norma yang tercermin dalam kehidupan spiritual dan sosial. Mahasiswa yang memiliki pengetahuan dan penguasaan konsep, teori, metode dan falsafah bidang ilmu secara sistematis yang diperoleh melalui penalaran dalam proses pembelajaran, pengalaman kerja dan penelitian. Serta mahasisswa yang memiliki kemampuan dalam unjuk kerja dengan menggunakan konsep, teori, bahan dan intrumen yang diperoleh melalui proses pembelajaran, pengalaman kerja, penelitian dan pengabdian pada masyarakat.

Pembelajaran kooperatif adalah model pembelajaran yang dirancang untuk membelajarkan kecakapan akademik (academic skill), sekaligus keterampilan sosial (social skill) termasuk interpersonal skill (Riyanto, 2009:271). Pembelajaran yang dilakukan memberikan pengalaman untuk mengembangkan kemampuan dalam suasana di sekolah, kemampuan berinteraksi di masyarakat dan juga dalam mengembangkan pribadi yang berkarakter. Dalam rangka meningkatkan kemampuan berfikir logis dan mengambil keputusan yang berbasis teman sebaya untuk bisa saling bekerja sama, model pembelajan kooperatif sangat disarankan untuk di gunakan. Slavin (Komalasari, 2010:62) mengatakan pembelajaran kooperatif adalah suatu strategi pembelajaran dimana siswa belajar dan bekerja dalam kelompok-kelompok kecil secara kolaboratif yang anggotanya terdiri dari 2 sampai 5 orang, dengan struktur kelompoknya bersifat heterogen.

Terdapat banyak model pembelajaran kooperatif yang bisa diaplikasikan kedalam proses pembelajaran sesuai dengan karakteristik dan perkembangan peserta didik. Model-model pembelajaran kooperatif diantaranya tipe numbered head together, tipe cooperative skript, tipe student team achievement division, tipe think pair and share, tipe jigsaw, tipe snowball throwing, tipe team game tournament, tipe cooperative integrated reading and composition dan tipe two stay two stray. Jigsaw merupakan model pembelajaran yang mengutamakan pengembangan berfikir kreatif dan belajar bekerja sama dengan teman. Menurut Sudarsana dkk (2014), tipe jigsaw adalah salah satu pembelajaran kooperatif dimana pembelajaran melalui kelompok kecil siswa yang bekerja sama dalam memaksimalkan kondisi belajar untuk mencapai tujuan pembelajarandan mendapatkan pengalaman belajar yang maksimal, baik pengalaman individu maupun pengalaman kelompok. Dalam pembelajaran siswa diberikan kesempatan untuk berkolaborasi dan bekerja sama dengan teman sebaya dalam bentuk diskusi kelompok dalam memecahkan suatu permasalahan yang diberikan oleh pendidik.

Pada dasarnya tipe jigsaw membagi materi yang cukup luas menjadi komponen-komponen kecil yang disebarkan kepada setiap orang dalam suatu kelompok, sehingga menjadi subtopik-subtopik yang perlu dipelajari oleh setiap individu dalam kelompoknya. Setiap peserta didik bertanggung jawab atas subtopik yang diperoleh dari hasil pembagian oleh pendidik.

Mata kuliah taekowndo adalah salah satu mata kuliah yang bersifat pilihan yang ditawarkan dalam struktur kurikulum Jurusan Pendidikan Jasmani, Kesehatan dan Rekreasi Fakultas Keguruan dan Ilmu Pendidikan di Universitas Siliwangi. Mata kuliah ini merupakan mata kuliah praktek dengan bobot 2 
sks dengan keseluruhan praktek. Mata kuliah ini berada pada semester genap dengan memberikan beberapa kajian materi diantaranya adalah teknik kuda-kuda, teknik pukulan, teknik tangkisan, teknik tendangan, peraturan pertandingan dan mempelajari rangkaian gerak dasar (poomsae). Target akhir yang ingin dicapai sebagai hasil akhir belajar mahasiswa pada mata kuliah taekwondo materi poomsae I adalah akumulasi dari nilai keterampilan poomsae I dan keaktifan yang muncul selama proses pembelajaran. Sehingga nilai yang muncul adalah nilai akhir yang terdiri dari nilai proses (observasi sikap) dan nilai hasil (keterampilan poomsae I).

Berkaitan dengan hal diatas bahwa pembelajaran selalu direncanakan dan didesain terlebih mulai dari mempersiapkan materi, peralatan yang dibutuhkan, metode yang akan digunakan sampai alternatif kegiatan bila terkendala hal-hal yang diluar kendali. Sehingga pada prosesnya nanti akan terlaksana dengan baik sesuai dengan rencana yang sudah dibuat. Disaat proses evaluasi akan sangat mudah bagi kita untuk menentukan mahasiswa mana yang sudah tuntas dan yang belum tuntas belajar.

\section{METODE}

Metode penelitian yang penulis lakukan yaitu dengan menggunakan metode penelitian tindakan (action research). Penelitian tindakan merupakan upaya mengujicobakan ide-ide kedalam praktik untuk memperbaiki atau mengubah sesuatu agar memperoleh dampak nyata situasi (Hasan Sangadji dan Sopiah, 2010). Seluruh ide yang muncul diantaranya bisa berupa perbaikan metode mengajar, media ajar, pengelolaan kelas atau pengembangan substansi dari materi yang akan diberikan kepada peserta didik dalam proses pembelajaran. Penyiapan dan pengambilan sampel dilakukan sebagai upaya peneliti untuk menetapkan bagian dari populasi dengan mempertimbangkan representasi dari elemen populasi untuk memperoleh data dan informasi penelitian (Indrawan dan Yaniawati, 2014 : 93). Dalam hal ini, untuk menentukan sampel penelitian adalah dengan cara sampel bertujuan (purposive sampling). Sampel yang menjadi subjek penelitian adalah kelas B yang jumlah anggota mahasiswa nya sebanyak 40 orang yang mengontrak mata kuliah Teori dan Praktek Taekwondo karena dari survey diketahui kelas ini yang paling kurang keterampilan poomsae I dibandingkan beberapa kelas yang lainnya. Instrumen yang digunakan dalam penelitian tindakan ini adalah teknik tes keterampilan dalam bentuk rubrik penilaian.

\section{HASIL DAN PEMBAHASAN}

Pembahasan hasil tindakan ini merupakan pembahasan yang dijelaskan dari hasil analisis dan pengolahan data dalam setiap siklus adalah sebagai berikut: Siklus I menunjukkan hasil penerapan model pembelajaran kooperatif tipe jigsaw terhadap hasil belajar keterampilan poomsae I pada mata kuliah T \& P Taekwondo adalah belum tuntasnya hasil belajar mahasiswa. Karena hasil dari observasi dan tes keterampilan poomsae I yang sudah dilaksanakan menunjukkan sebanyak 28 orang atau sebesar 70,5 \% yang sudah masuk kedalam kriteria ketuntasan (kelulusan) minimal. Ini menjelaskan bahwa secara keseluruhan masih kurangnya kemampuan mahasiswa dalam mempelajari keterampilan poomsae I karena persentasenya kriteria ketuntasan (kelulusan) minimal (KKM) masih dibawah 75\%. Hal ini disebabkan karena beberapa hal, diantaranya adalah : motivasi mahasiswa masih kurang, mahasiswa masih banyak yang tidak mampu memahami materi lewat media gambar tanpa keterangan atau penjelasan setiap gambarnya, mahasiswa masih bersikap individualistik, tidak jelasnya teknis dalam pembelajaran kelompok, proses pengawasan dosen kurang, waktu belajar dengan kelompok asal dan kelompok ahli sangat terbatas, sebelum akhir pembelajaran tidak ada kegiatan penyeragaman gerakan. Maka dari itu perlu dilanjutkan ke dalam siklus II dengan memperbaiki setiap kesalahan atau kekurangan dari siklus I, agar hasil belajar pada siklus berikutnya bisa meningkat. Siklus II menunjukkan hasil belajar yang lebih baik atau lebih meningkat secara signifikan. Hal ini ditunjukkan oleh hasil analisis dan pengolahan data mengenai pencapaian kriteria ketuntasan (kelulusan) minimal 
hasil belajar mahasiswa yang sudah mencapai $87,5 \%$ yaitu sebanyak 35 orang. Artinya secara keseluruhan mahasiswa kelas B sudah memenuhi kriteria ketuntasan (kelulusan) minimal 75\% terhadap hasil belajar poomsae I dengan menggunakan penerapan model pembelajaran kooperatif tipe jigsaw. Hal ini membuktikkan bahwa penerapan model pembelajaran kooperatif tipe Jigsaw mampu meningkatkan hasil belajar keterampilan poomsae I dalam mata kuliah T \& P Taekwondo pada mahasiswa kelas B Jurusan Pendidikan Jasmani, Kesehatan dan Rekreasi tahun ajaran 2016/2017.

\section{KESIMPULAN}

Penerapan model pembelajaran kooperatif tipe jigsaw memberikan pengaruh yang berbarti terhadap peningkatan hasil belajar keterampilan poomsae I mata kuliah T \& P Taekwondo pada mahasiswa kelas B Jurusan Pendidikan Jasmani Kesehatan, dan Rekareasi tahun ajaran 2016/2017. Hal ini ditunjukkan dengan hasil peningkatan belajar yang sudah mencapai KKM adalah sebanyak 35 orang atau sebesar $87,5 \%$. Ini berarti seluruh mahasiswa sudah melebihi $75 \%$ dari kriteria ketuntasan (kelulusan) minimal.

\section{DAFTAR PUSTAKA}

Indrawan, Rully dan Poppy Yuniawati. (2016). Metodologi Penelitian Kuantitatif, Kualitatif dan Campuran untuk Menejemen, Pembangunan dan Pendidikan. Bandung: PT. Refika Aditama

Jurnal Hasil Riset, http://www.e-jurnal.com/2013/11/pengertian-hasil-belajar.html diakses pada tanggal 23 November 2013

Komalasari, Kokom. (2010). Pembelajaran Kontekstual Konsep dan Aplikasi. Bandung: PT. Refika Aditama.

Mulyasa, (2009). Implementasi Kurikulum Tingkat Satuan-Pendidikan Kemandirian Guru dan Kepala Sekolah. Jakarta: Bumi Aksara.

Munasih, Siti. (2016). Meningkatkan Kreatifitas Gerak Dasar Lempar Tangkap Bola Lunak melalui Pembelajaran Jigsaw. Jurnal Penelitian Tindakan Kelas. Pekalongan. Volume 17 No. 1, 2016.

Nurhasan dan Abdul Narlan. (2004). Tes dan Pengukuran Pendidikan Olahraga. Pendidikan Jasmani, Kesehatan dan Rekreasi. Universitas Siliwangi.

Riyanto, Yatim. (2009). Paradigma Baru Pembelajaran. Jakarta: Kencana Prenada Media Group.

Sangadji, Etta Mamang dan Sopiah. (2010). Metodologi Penelitian-Pendekatan Praktis dalam Penelitian. Yogyakarta: CV. ANDI Offset.

Siswanto, Heri. (2013). Pembelajaran Kooperatif Tipe Jigsaw untuk Meningkatkan Keterampilan Bola Voli dan Bola Basket Siswa SMK. Jurnal Media Ilmu Keolahragaan Indonesia. Universitas Negeri Semarang. Volume 3 No. 3, 2013.

Subiantoro, Fendi dan Taufik Hidayat. (2013). Penerapan Model Pembelajaran Cooperative Learning (Jigsaw) terhadap Hasil Belajar Service Bola Voli. Jurnal Pendidikan Olahraga dan Kesehatan. Universitas Negeri Surabaya. Volume 1 No. 2, 2013.

Sudarsana, I KM dkk. (2014). Implementasi Model Pembelajaran Kooperatif Jigsaw I Untuk Meningkatkan Aktivitas dan Hasil Belajar Passing Control Sepakbola. E-Jurnal PJKR Universitas Pendidikan Ganesha. Volume 1, 2014.

Sugiartana, Made dkk. (2014). Penerapan Kooperatif Jigsaw I untuk Meningkatkan Aktivitas dan Hasil Belajar bola Voli. E-jurnal PJKR Universitas Pendidikan Ganesha. Volume 1, 2014. 
Sukmadinata, Nana Syaodih, (2010). Metode Penelitian Pendidikan. Bandung: PT. Remaja Rosdakarya.

Suwiwa, I Gede. (2015). Penerapan Model Pembelajaran Kooperatif Tipe Jigsaw untuk Meningkatkan Aktivitas dan Hasil Belajar Mata Kuliah Teori dan Praktek Renang II. Jurnal Pendidikan Indonesia. Universitas Pendidikan Ganesha. Voluma 4 No. 2, 2015.

Undang-Undang RI No. 20 tahun 2003. Sistem Pendidikan Nasional. Undang-Undang Republik Indonesia. Jakarta.

Undang-Undang RI No. 12 tahun 2012. Pendidikan Tinggi. Undang-Undang Republik Indonesia. Jakarta.

Universitas Siliwangi, (2012). Pedoman Akademik Tahun 2012/2013. Tasikmalaya. Universitas Siliwangi.

Wikipedia, https://id.wikipedia.org/wiki/Pendidikan?veaction=edit diakses pada tanggal 15 Maret 2016

Yulaikah, Mei. (2013). Penerapan Jigsaw untuk Meningkatkan Hasil Belajar Siswa Sekolah Dasar. EJurnal Dinas Pendidikan. Surabaya. Volume 6, 2013. 